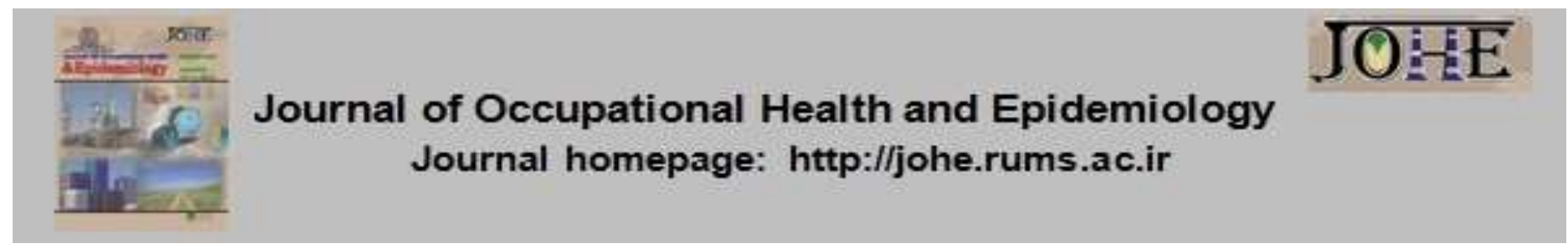

\title{
Incidence Rate and Epidemiological Aspects of Injuries Due to Accidents in Khomein City, Iran (2018)
}

\author{
Yasan Kazemzadeh ${ }^{1 *}$, Mohamad Ali Orouji ${ }^{2}$, Mojtaba Didehdar ${ }^{3}$, Javad Nazari ${ }^{4}$, Majid Pishvar ${ }^{5}$, \\ Mohamad Moazeni ${ }^{5}$, Heshmatola Rezai ${ }^{6}$, Abouzar Raeisvandi ${ }^{7}$
}

1- MSc in Epidemiology, Dept. of Health, Khomein Faculty of Medical Sciences, Khomein, Iran.

2- Assistant Prof., School of Nursing and Midwifery, Khomein Faculty of Medical Sciences, Khomein, Iran.

3- Assistant Prof., Dept. of Medical Mycology and Parasitology, Arak University of Medical Sciences, Arak, Iran.

4- Assistant Prof., Dept. of Pediatrics, Arak University of Medical Sciences, Arak, Iran.

5- MSc in Strategic Management, Dept. of Health, Khomein Faculty of Medical Sciences, Khomein, Iran.

6- General Practitioner, Khomein Health Center, Khomein Faculty of Medical Sciences, Khomein, Iran.

7- MSc in Epidemiology, Avaj Health Center, Qazvin University of Medical Sciences, Qazvin, Iran.

\section{Article Info}

* Corresponding author:

Yasan Kazemzadeh, E-mail:

yasankazemzadeh@ gmail.com

\section{Article history}

Received: Dec 2020

Accepted: Dec 2021

10.29252/johe.9.3.133

Print ISSN: 2251-8096 Online ISSN: 2252-0902

Peer review under responsibility of Journal of Occupational Health and Epidemiology

\author{
Citation: Kazemzadeh Y, Orouji MA, Didehdar M, Nazari J, Pishvar M, Moazeni M, Rezai H, \\ Raeisvandi A. Incidence Rate and Epidemiological Aspects of Injuries Due to Accidents in \\ Khomein City, Iran (2018). JOHE 2020; 9(3):133-9.
}

\begin{abstract}
Background: Accidents and injuries are one of the most important causes of disability and death in developing countries. This study was conducted to determine the incidence rate and epidemiological characteristics of accidents in the Khomein city.

Materials and Methods: This cross-sectional descriptive study was done by national program of accidents and injuries registry data in the Khomein city ( $n=986)$. To calculate the annually Incidence Rate (IR) and age-standardized incidence rate (ASR), the world standard population was used. Chi-square and independent t-test were used to examine the relationship or difference between variables.

Results: The mean age of the injured cases was $33 .{ }^{\circ} \pm 18.2$ year. The annually Incidence Rate (IR) of accidents and injuries was 941.2 cases per 100,000, while the agestandardized incidence rate (ASR) were estimated 919 per 100,000 people. The sex ratio (male to female) in all accidents was 2.45. The most incidents occurred in both sexes were reported car accidents (32.55\%), motorcycle accidents (31.8\%), pedestrian accidents (16.5\%) and poisoning (6.18\%), respectively. Significant difference was observed between gender and type of incidents. Suicide attempts in the female group were 6.5 times higher than the male group.

Conclusion: The incidence rate of traffic crashes in the city of Khomein is several times higher than provincial and national levels. Therefore, should be In addition to the optimizing the roads and removing the Accident-prone spots. The high occurrence of poisonings and suicide attempt in the women's group is warning danger for the authorities to take preventive policies and applying cultural mechanisms to reduce this ratio.
\end{abstract}

Keywords: Accidents, Epidemiologic, Injuries, Incidence.

\section{Introduction}

Accidents and injuries are recognized as one of the most important causes of disability and death in developed and developing countries (especially Iran) [1]. In recent decades Accidents increased due to urbanization (increasing number of cars and machinery) and increasing industrialization of societies and considered as a public health problem in all countries [2]. Injury-related to accidents will be the second leading cause of 
disability in developing countries by 2006, and the third cause of death and disability around the world [3]. Accident is an unexpected event by individual which there isn't any intention or previous planning for it and its' vulnerable effects is detectable. In other words accident is an unexpected event caused by humans and the results of which is detectable damage $[4,5]$.

According to the World Health Organization (WHO) resources, more than 5 million deaths annually occur in worldwide due to various accidents and injuries that means about 14,000 people die every day due to injuries which accounts for $9 \%$ of the total deaths in the world [6]. Global studies show that deaths from accidents in men and women are $1.8 \%$ and $5 \%$ of all deaths respectively [7]. Approximately, ten million people in worldwide suffer from non-fatal injuries and accidents [8]. Total years of life lost due to accidents are more than other causes of death and at the global level, it accounts $15 \%$ of the total years of life lost. Therefore, it is expected to increase significantly in the future and also most of the economic and social damages of accidents occur in under developed countries $[9,10]$. According to investigations, accidents in Iran are more different than other parts of the world. Of the 4 million hospitalizations cases in Iran, 1.5 million is related to accidents [11]. The deaths due to accidents in Iran are in line with the industrialization process of societies so that injury and accidents after cardiovascular disease are the second cause of death of all causes of death and also are the first cause of death among people with the age range of 5 to 49 years [12, 13]. Based on diseases estimations in Iran, accidents have the highest burden of disease among other diseases and caused more than 2 million years of life lost due to premature death and disability [14]. Traffic accidents with about 32 deaths per 100000in Iran annually is one of the main causes of deaths from accidents and also is the first cause of years of life lost [13]. The study of Farzandipour et al. showed that in 2004, 6415 people had accident or injured [11]. According to results of a study that performed in Tehran, due to accidents an average of 200 people died and 1,200 people injured per month [15]. Findings of studies conducted in southeastern of Iran and also a nationwide study on 9.2 million injuries recorded in 28 provinces of the country demonstrated that traffic accidents fall and hit are known generally as the most common accidents in the country [16]. The costs of resulting from injuries to societies are very high due to the involvement of all age groups. In this regard, studies have shown that 28 percent of hospital costs are due to accidents in the elderly which this can be consider as an indication of high severity of the incidents in this age group [17]. Due to the economic burden and social consequences of accidents and the impacts that accidents have on the quality of life index and disability adjusted life years (DALY) and also because there is little information about epidemiological situation and incidence of accident in Khomein city, therefore, evaluation of epidemiologic trend of this event and awareness of dimensions of the occurrence of injuries caused by accidents and related variables for health investors can be valuable and can give a clear picture of the issue to health practitioners and finally resulting in better prevention and prioritizing your health plans. Therefore, this study conducted to survey of epidemiological status of injuries caused by accidents and also estimation the incidence of accidents in the Khomein city.

\section{Materials and Methods}

This applied descriptive-correlational study was conducted based on structural equation modeling. The statistical population included all employees of Maron Company, Ahvaz City, in 2019. A sample of 220 employees was selected by random sampling from different organizational units of administrative services, technical services, operations, repairs, warehousing, security, training, and quality assurance. All participants answered the questionnaires, yet the final sample size was 210 due to the elimination of incomplete questionnaires (the response rate of $95.45 \%$ ). According to the number of direct paths $(n=6)$, exogenous variables $(n=3)$, covariance $(n=3)$, and error variances $(n=4)$, 16 parameters were calculated.

Considering this cross-sectional descriptive study was carried out in the Khomein city (One of the county of Markazi province, this cross-sectional descriptive study was carried out in the Khomein city (One of the county of Markazi province, Iran) by using recordings data collected from national program of injury and accidents during March 2018 to March 2019.

The study population consisted of all victims and patients due to accidents (which to receive carepalliative) were admitted to Khomein city hospitals or was transferred to the hospital by 115 emergency center and provided therapies for them outpatient or hospitalization. In this study, the sample size was determined by census method. It should be noted that accident and injuries whose data were not fully recorded were excluded (such as death at the accident site or mild injuries and no hospital attendance).

The source of data collection was based on integrated accident and injury record system and 
city events. Tool of data collection was a Special form from accident and injury record system of Iran. This form contains information such as name, age, gender, accident area, accident location, and accident type, Date of accident, consequences of accident and the name of the registrar center. Information about injuries and accidents in this form was completed by nurses and doctors in hospitals and then transferred to the health center periodically. In health center, data was record in national system of registration of injuries caused by accidents. In order to calculate the Incidence Rate (IR) of injuries by type of incident, the coefficient of 100 thousand people and the population of the city (in 2018) were considered. The standardized population was also used to determine Age-Standardized Incidence Rate (ASR). Data was analyzed by using SPSS version 20. Mean and standard deviations (SD) were reported for quantitative variables, and frequency tables and charts were reported for nominal and rank variables. Chi-square and independent t-test were used to examine the relationship or difference between the variables. In all stages of statistical analysis, the significance level was considered to be less than 0.05 .

\section{Results}

In 2018, a total of 986 accidents were reported in the Khomein city, whiles $701(71.1 \%)$ were men and $285(28.9 \%)$ were women. The age range of individuals from 2 months to 93 years, and the mean (SD) of age were determined to be $33.5 \pm 18.2$ years. The mean (SD) of age in men was $33.1 \pm 18.2$ years and for women was 33.9 \pm 19.4 years, which significant association was not observed $(P=0.329)$ between the ages of men and women. In this study, the annually Incidence Rate (IR) of accidents from all types were estimated to be 941.2 cases per 100,000 people, while the agestandardized incidence rate (ASR) for all types of accidents was 919 per hundred thousand people. In addition, the incidence of accidents (IR) in men 1297 in 100,000 and in women 558.3 in 100,000 people was declared and these values for ASR in men and women were 1263.8 and 548.2 cases per hundred thousand people, respectively. In all age groups except the age group of 90-99 years, the occurrence of accidents in men was higher than of women, and the most frequency in both sexes was related to the age group of 20-29 years old (Table 1 ). In total, the sex ratio (male to female) in all accidents is 2.45 , that this proportion in the age group of 20-29 years was maximum.

Table 1. Frequency distribution of accidents in Khomein city based on age group and gender, 2018.

\begin{tabular}{ccccc}
\hline Age group & Male & Female & Total (percent) & Male to female ratio \\
\hline $9-0$ & 58 & 31 & $89(9)$ & 1.87 \\
\hline $19-10$ & 118 & 46 & $164(16.6)$ & 2.56 \\
\hline $29-20$ & 181 & 42 & $223(22.6)$ & 4.3 \\
\hline $39-30$ & 142 & 69 & $211(21.3)$ & 2.05 \\
\hline $49-40$ & 71 & 34 & $105(10.6)$ & 2.08 \\
\hline $59-50$ & 59 & 29 & $88(8.9)$ & 2.03 \\
\hline $69-60$ & 34 & 18 & $52(5.2)$ & 2.1 \\
\hline $79-70$ & 25 & 11 & $37(3.7)$ & 4 \\
\hline $89-80$ & 12 & 3 & $15(1.5)$ & 0.5 \\
\hline $99-90$ & 1 & 2 & $3(0.3)$ & 2.45 \\
\hline Total & 701 & 285 & $986(100)$ & \\
\hline
\end{tabular}

In terms of seasonal distribution, generally, we have witnessed more accidents occur in summer season $(30.9 \%)$, and in terms of the months of the year, the month of December with $12.3 \%$ cases allocated to the highest (Fig. 1). 


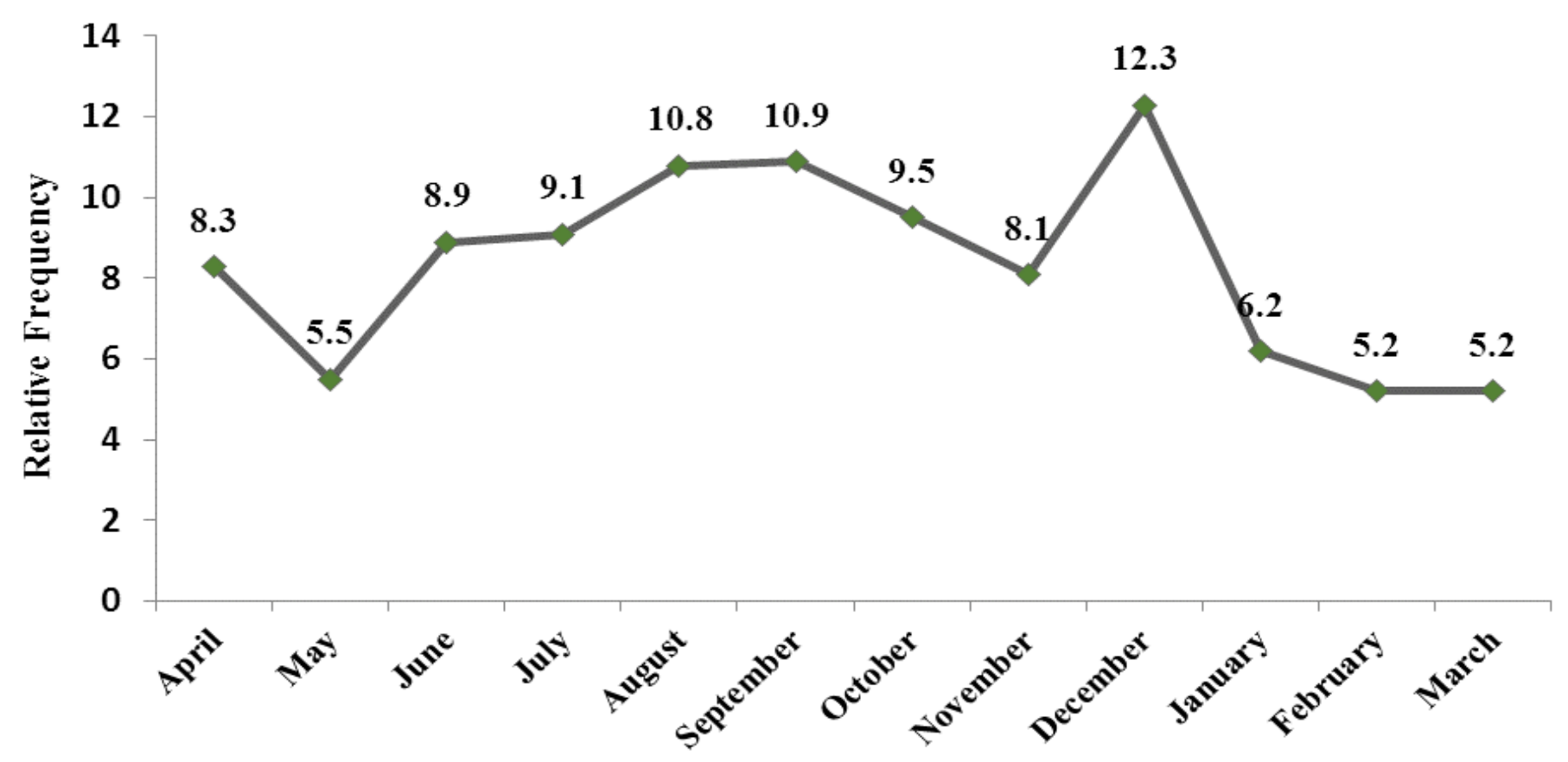

Fig. 1. Distribution of relative frequency of accidents in terms of months of the year in Khomein city, 2018.

In terms of incident area, $61.05 \%$ cases of the accidents occurred at the city level and regarding to the location of the incident occurrence, the most of the cases have been reported from Alley and
Avenue (52.5\%) and Road and Highway (30.2\%) (Table2). There was a significant difference between the variables studied in this table and the gender of injured people $(P<0.001)$.

Table 2. Frequency distribution of accidents in Khomein city based on area and location of the incident occurrence, differentiated by gender, 2018

\begin{tabular}{|c|c|c|c|c|c|}
\hline & Variables & Male (\%) & Female (\%) & Total (\%) & P-value \\
\hline \multirow{4}{*}{ Incident area } & Town & $451(64.33)$ & $151(52.9)$ & $602(61.05)$ & \multirow{4}{*}{$P<0.001$} \\
\hline & Village & $67(9.55)$ & $17(5.96)$ & $84(8.51)$ & \\
\hline & Out of town and village & $183(26.1)$ & $117(41)$ & $300(30.42)$ & \\
\hline & Total & $701(100)$ & $285(100)$ & $986(100)$ & \\
\hline \multirow{8}{*}{$\begin{array}{l}\text { Accident } \\
\text { location }\end{array}$} & Road and highway & $183(61.4)$ & $118(38.6)$ & $298(30.2)$ & \multirow{8}{*}{$P<0.001$} \\
\hline & At home & $64(54.2)$ & $54(45.8)$ & $118(11.9)$ & \\
\hline & Workplace & $24(100)$ & 0 & $24(2.4)$ & \\
\hline & Public places & $18(94.7)$ & $1(5.3)$ & $19(1.9)$ & \\
\hline & School, educational places & $2(100)$ & 0 & $2(0.2)$ & \\
\hline & Alley and avenue & $406(78.3)$ & $112(21.6)$ & $518(52.5)$ & \\
\hline & Other & $4(100)$ & 0 & $4(0.4)$ & \\
\hline & Total & $701(100)$ & $285(100)$ & $986(100)$ & \\
\hline
\end{tabular}

Table 3 demonstrated that the frequency of injuries is different by gender based on the type of incident. The most of the incidents occurred in both sexes were motor vehicle (car) accident (32.55\%), motorcycle accident $(31.8 \%)$, pedestrian accident $(16.5 \%)$ and poisoning (6.18\%) respectively. Motorcycle crashes, car crashes and pedestrian accidents were the most frequent accident among men, and also car accidents, pedestrian accidents and poisoning were the main causes of referral to hospital among women. A significant difference was observed between gender and type of incident $(\mathrm{P}<0.001)$. 
Table 3. Frequency distribution of accidents injuries in Khomein city in terms of the type of incident, differentiated by gender, 2018.

\begin{tabular}{ccccc}
\hline Type of incident & Male (\%) & Female (\%) & Total (\%) & P-value \\
\hline Electric shock & $8(1.14)$ & 0 & $8(0.8)$ & $<\mathbf{0 . 0 0 1}$ \\
\hline Poisoning & $26(3.70)$ & $35(12.28)$ & $61(6.18)$ & $<\mathbf{0 . 0 0 1}$ \\
\hline Burn & $6(0.85)$ & 0 & $6(0.6)$ & $<\mathbf{0 . 0 0 1}$ \\
\hline Falling & $32(4.56)$ & $18(6.31)$ & $50(5.07)$ & $<\mathbf{0 . 0 0 1}$ \\
\hline Car accident & $191(27.24)$ & $130(45.61)$ & $321(32.55)$ & $<\mathbf{0 . 0 0 1}$ \\
\hline Motorcycle accident & $297(42.3)$ & $17(5.96)$ & $314(31.8)$ & $<\mathbf{0 . 0 0 1}$ \\
\hline Pedestrian accident & $85(12.1)$ & $78(27.36)$ & $163(16.5)$ & $<\mathbf{0 . 0 0 1}$ \\
\hline Animal attack & $5(0.72)$ & $3(1.05)$ & $8(0.81)$ & $<\mathbf{0 . 0 0 1}$ \\
\hline Snake and scorpion bites & $15(2.16)$ & $2(0.7)$ & $17(1.72)$ & $<\mathbf{0 . 0 0 1}$ \\
\hline Violence & $23(3.28)$ & 0 & $23(2.33)$ & $<\mathbf{0 . 0 0 1}$ \\
\hline Other & $13(1.85)$ & $2(0.7)$ & $15(1.52)$ & $<\mathbf{0 . 0 0 1}$ \\
\hline Total & $701(100)$ & $285(100)$ & $9 \wedge$ r $(100)$ & $<\mathbf{0 . 0 0 1}$ \\
\hline
\end{tabular}

Incidence rate of all types of traffic accidents in the Khomein city was 753.6 per 100,000 people $(7.53$ per thousand people) among both gender and also 1049.1 and also 438.8 per 100,000 people $(7.53$ per thousand people) of IR was reported among men and women, respectively. In the present study, the incidence rate of traffic accidents in motorcyclists was 29.8 cases per 10,000 people (2.98 per thousand), which in terms of gender, among men 54.6 per 10,000 and in women 3.52 in 10,000 people was announced. In addition, in this study, the incidence rate of pedestrian traffic accidents was declared 152.2cases per 100,000 people (1.52 per thousand), which these values in men and women was found to be 153.5 and 150.8 cases per 100,000 people, respectively. According to the findings, status of $55.7 \%$ of poisoned cases due to suicide attempt, $8.2 \%$ of cases due to intent of violence and $26.2 \%$ of cases due to the intentional accidents are mentioned uncertain. Moreover, only $9.8 \%$ of poisoned cases occurred unintentionally. Cases of suicide attempt among female group with $9.5 \%$ were 6.5 times higher than men group with $1.4 \%$ suicide attempt.

\section{Discussion}

This research is the first study to in the field of Epidemiological characteristics of accidents in the city of Khomein. It's one of the few studies that all aspects of the accidents are investigated in one place, and the estimation of ASR was used to examine the difference of age composition. Based on the results of this study, incidence rate and ASR of accidents were 941.2 and 919 per hundred thousand, respectively. This rate is higher than average rates of accidents in the provincial level (Central Province) and less than average rates of accidents in the national level [18].Therefore,
Khomein city is one of the regions with a moderate risk of accidents. The results of this study showed that men $(71 \%)$ are faced with the risk of accidents more likely than women; these results were consistent with study of Abdulvand et al [19] and Vafaei et al [16]. In addition, a higher incidence of high-risk behaviors in men was indicated, and also the more presence of men in daily life activities was reported. In the present study, the average age of the injured persons was 33.5 years, and a high percentage of injury was seen in the age group of 20-29 years. Also, several studies confirmed that accidents occur at young ages [20, 21]. In the study of Aladelus et al, In Nigeria, most of the injuries were reported in the age group of 21-30 years [22]. Because young people are more active, therefore, they are more at risk. On the other hand, emotional and high-risk behaviors and lack of attention to driving laws by these people is more happen. The most of the accidents happened in urban areas (61.05\%) and Alley and Avenue $(52.5 \%)$, respectively which is consistent with other studies [23]. According to the present study, most of the accidents were car accidents, motorcycle accidents, pedestrian accidents and poisoning. In the study of Khazaee et al in Iran,the most accidents were related to the hit $(22.2 \%)$, automobile accident (21.7\%) and fall (10.6), respectively [24]. While in the study of Al-Kandar et al in Kuwait [25] and Sharma et al in Nepal [26] the most injuries, respectively $13.1 \%$ and $42.2 \%$ were due to fall down. These results were not consistent with the results of present study, sowe need continuing inter-institutional cooperation in the traffic accident section and also basic training for high-risk groups.

The results of this study showed that suicide attempts in the women group were 6.5 times 
higher than that of men group, which was more numerically and more critical than other studies [24].In addition, the incidence of all types of traffic accidents was reported 753.6 per 100,000 (7.33 per thousand), which is higher than other studies in the country $[27,28]$. Also, the findings of this study indicated that the incidence of traffic accidents in motorcyclists and pedestrians was 29.8 cases per 10,000 people (2.98 per thousand) and 152.2 cases per 100 thousand people (1.52 per Thousand), respectively. According to a study conducted by Gholamali et al, in the Iran, the incidence of traffic accidents in motorcyclists in the whole country was 24 . 7 per 10,000 thousand people and in the central province was 13.03 per 10,000 people [29]. In another study that was done by Abraham Kia et al, on the pedestrians, the incidence of pedestrian traffic accidents in Iran was reported $64.8 \%$ in the case of 100 thousand people and in the central province $19.8 \%$ in the case of 100 thousand people [30]. It demonstrated lower rates compared to the present study. So, the study area is considered as a high risk area for motorized traffic accidents and pedestrians in Iran. One of the limitations of the current study was that only information from injured patients who were referred to the hospital or referred to the emergency department was used and minor damage which were treated at home or in health care centers were not included. So, other sources of information should be used in future studies.

Considering the difference between the results of IR and ASR in this study, it is suggested that in the future studies of other regions of the country, the ASR index should be used to calculate incidence and representation the effects of age difference to make more accurate interpretation of the findings in this kind of the studies. It is suggested that increasing driver awareness about accidents be on the agenda. It is suggested that the police impose stricter legal requirements to prevent traffic accidents.It is suggested that the Ministry of Health, the Ministry of Labor and other organizations of the country, such as the Ministry of Roads and Urban Development, prepare a comprehensive program to reduce the number of accidents and train people.

\section{Conclusion}

In general, the results of this study showed that the average of incidence of traffic accidents in Khomeini is several times high than provincial and national levels. Therefore, this city is one of the high-risk areas of traffic accidents in the country. In this regard, improving safety of the roads, repairing parts of the roads which make accident, holding regular meetings with safe community committee and traffic police to take approaches for reducing dangerous behaviors by young drivers and finally reducing traffic injuries are necessary. In addition, the most accidents have occurred in the young age group, so, paying attention to this sensitive group is important. On the other hand, high incidence of poisoning and suicide attempt in women is an alarm for authorities to do appropriate educational and interventional accomplishments to prevent similar occurrences.

\section{Acknowledgement}

Hereby, we extend our gratitude to the Department of Health at Khomein Faculty of Medical Sciences for providing the data for this study.

Conflict of interest: None declared.

\section{References}

1. Majori S, Bonizzato G, Signorelli D, Lacquaniti $S$, Andreetta L, Baldo V. Epidemiology and prevention of domestic injuries among children in the Verona area (north-east Italy). Ann Ig 2002; 14(6):495-502.

2. Souri H. Epidemiology study of accidents in children referred to the emergency department of Ahvaz hospitals. Jundishapur Scientific Medical Journal 2002; 32:1-11.

3. Garg N, Hyder AA. Exploring the relationship between development and road traffic injuries: a case study from India. Eur J Public Health 2006; 16(5):487-91.

4. Khosravi S, Ghafari M. Epidemiological survey of domestic accidents in urban and rural area of Shahrekord in 1999. Journal of Shahrekord University of Medical Sciences 2003; 5(2):5364.

5. Mazloumi S, Fallah Zadeh H. Prevalence of accidents in individuals under 20 years old in Yazd, Iran. Payesh (Health Monitor) 2002; 1(4):21-5.

6. World Health Organization. Injuries and violence: the facts 2014. Geneva, Switzerland: World Health Organization; 2014.

7. World Health Organization. The Global Burden of Disease: 2004 Update. Geneva, Switzerland: World Health Organization; 2008.

8. Gorman DR, Ramsay LJ, Wilson GS, Freeland P. Using routine accident and emergency department data to describe local injury epidemiology. Public Health 1999; 113(6):2859.

9. Neghab M, Habibi $M$, Rajaeefard A, Choobineh A. Home Accidents in Shiraz during a 3-year Period (2000-2002). Journal of Kermanshah University of Medical Sciences 2008; 11(4):e80470.

10. Lozano R, Naghavi M, Foreman K, Lim S, Shibuya K, Aboyans V, et al. Global and 
regional mortality from 235 causes of death for 20 age groups in 1990 and 2010: a systematic analysis for the Global Burden of Disease Study 2010. Lancet 2012; 380(9859):2095-128.

11. Farzandipour M, Ghattan H, Mazrouei L, Nejati M, Aghabagheri T. Epidemiological Study of Traumatic Patients Referred to Neghavi Hospital of Kashan. Journal of Kermanshah University of Medical Sciences 2007; 11(1):e81870.

12. Naghavi M. Transition in Health Status in the Islamic Republic of Iran. Iranian Journal of Epidemiology 2006; 2(1):45-57.

13. Taravatmanesh S, Hashemi-Nazari SS, Ghadirzadeh MR, Taravatmanesh L. Epidemiology of fatal traffic injuries in the Sistan and Baluchistan province in 2011. Journal of Safety Promotion and Injury Prevention 2015; 3(3):161-8.

14. Naghavi M, Abolhassani F, Pourmalek F, Jafari $\mathrm{N}$, Moradi Lakeh M, Eshrati B, et al. The Burden of Disease and Injury in Iran in the Year 2003. Iranian Journal of Epidemiology 2008; 4(1):119.

15. Akaberi A, Hekmatshoar R, Fallahi M, Razavi SM. Prevalence of musculoskeletal disorders and it's risk factors among, mothers' home working. Journal of Sabzevar University of Medical Sciences 2013; 19(4):395-9.

16. Vafaei R, Hatamabadi HR, Hadadi M, Souri $\mathrm{H}$, Esmaili A, Akbarpoor $\mathrm{S}$, et al. Investigation of the epidemiological situation of traffic accidents leading to injuries on the Tehran-Abali road in 2008 by police reports. Journal of Knowledge \& Health in Basic Medical Sciences 2010; 5(Supplement):74-74 .

17. Norian R, Gholam Aliei B, Afshari M, Kangavari M. Related Factors with Injuries Caused by Accidents in the Elderly Referred to Hospital of Tuyserkan city in 2013. Journal of Sabzevar University of Medical Sciences 2015; 22(1):12331.

18. Department of Accident Prevention of Medical Universities of Iran, Ministry of Health and Medical Education. National report of accident registration, 2015-2016. Tehran, Iran: Accident Prevention Office, Office of Non-Communicable Diseases Managemen, Ministry of Health and Medical Education; 2017. p52.

19. Abdolvand M, Bahadori Monfared A, Khodakarim S, Farsar AR, Golmohamadi A, Safaei A. Evaluation of Accidents and Incidents at Injury Registered in Medical Centers Affiliated to Shahid Beheshti University of Medical Sciences (2012-2013). Journal of Safety Promotion and Injury Prevention 2014; 2(1):6572.
20. Charkazi A, Esmaeili A, Garkaz G, Qoreishi Z, Gerey S, Nazari S. Epidemiologic Survey of Road Traffic Accidents in Patients Admitted in Emergency Department of Alejalil Hospital in Aq-Qala City, Golestan Province. Journal of Health 2012; 3(2):42-9.

21. Hadaye RS, Rathod S, Shastri S. A crosssectional study of epidemiological factors related to road traffic accidents in a metropolitan city. J Family Med Prim Care 2020; 9(1):168-72.

22. Aladelusi TO, Akinmoladum IV, Olusanya OO, Akadiri OA, Fasola AO. Evaluation of pedestrian road traffic maxillofacial injuries in a Nigerian tertiary hospital. Afr J Med Med Sci 2014; 43(4):353-9.

23. Moosazadeh $M$, Nasehi MM, Mirzajani $M$, Bahrami MA. Epidemiological Study of Traumatic Injuries in Emergency Departments of Mazandaran Hospitals, 2010. Journal of Mazandaran University of Medical Sciences 2013; 23(98):144-54.

24. Khazaei S, Mazharmanesh S, Khazaei Z, Goodarzi E, Mirmoini R, Mohammadian Hafshejani A, et al. An epidemiological study on the incidence of accidents in the Hamedan province during 2009 to 2014. Pajouhan Scientific Journal 2016; 14(2):8-16.

25. Al-Kandary N, Al-Waheeb S. Patterns of accidental deaths in Kuwait: a retrospective descriptive study from 2003-2009. BMC Public Health 2015; 15:302.

26. Sharma D, Panta PP, Amgain K. An Epidemiological Study of Injuries in Karnali, Nepal. J Emerg Trauma Shock 2020; 13(1):304.

27. Taravatmanesh S, Hashemi Nazari SS, Ghadirzadeh MR, Taravatmanesh L. Epidemiology of Fatal Traffic Injuries in the Sistan and Baluchistan Province in 2011. Journal of Safety Promotion and Injury Prevention 2015; 3(3):161-8.

28. Khazaie S, Mohammadian Hafshejani A, Mohammadian M, Salehiniya $H$, Afshari M. An epidemiologic survey of traffic accidents on Iran drivers in 2013. Journal of Rescue Relief 2015; 7(1):51-60.

29. Gholamaliee B, Khazaei S, Jamorpour S, Mohammadian Hafshejani A, Salehinia $H$. Epidemilogical assessing of motorcyclists country-level traffic accidents, 2013. Pajouhan Scientific Journal 2015; 14(1):12-21.

30. Ebrahimi Kebria S, Soori H. Study of epidemiological pattern of pedestrian's road traffic injuries in 2014 and determination of related risk factors on severity of injury. Payesh (Health Monitor) 2017; 16(3):293-302. 